ISBN: 978-980-427-021-5

\title{
Discapacidad y procesos de intervención social en salud $^{1}$
}

\author{
Francis Araque Barboza², Mery Cunha Fernández ${ }^{3}$
}

\section{Resumen}

Este artículo es producto de una investigación cualitativa, hermenéutica donde se exponen los procesos de intervención en salud llevados a cabo por los programas académicos de la Universidad Metropolitana en el Centro Educativo de habilitación y rehabilitación Ce Camilo de Barranquilla, en el marco de los proyectos institucionales del periodo enero 2009 hasta junio 2016. Su propósito es analizar los resultados de las prácticas formativas de los estudiantes en los escenarios atendidos, contribuyendo de esta manera en la calidad de vida de la comunidad intervenida y por consiguiente en su entorno. En el desarrollo del artículo se presentan los referentes teóricos relacionados con el tema en estudio, partiendo del concepto de discapacidad, prácticas formativas de los estudiantes y, finalmente se describen las actividades que se desarrollaron en el periodo analizado. Es de anotar, que en la realización de esta investigación se han tenido en cuenta los lineamientos propuestos por el Ministerio de Educación y Protección Social de Colombia en el decreto 2376 del 1 de Julio del 2010. En el artículo N²: "el cual tiene como objeto regular los aspectos atinentes de la relación docencia-servicio en programas académicos del área de la salud". Así, desde este plano de análisis, se enfoca la atención a los escenarios de intervención en salud para promover la importancia de repensar en políticas públicas de inclusión social que fortalezcan el tema de los derechos de personas discapacitadas en Colombia.

Palabras clave: discapacidad, prácticas formativas, procesos de intervención, calidad de vida.

1 Este artículo es producto de una investigación original titulada: "Ce Camilo una mirada al abordaje comunitario desde la investigación acción participativa"

2 Dra. en Ciencias Humanas, Magister en Gerencia Pública, Socióloga. Docente e Investigadora de la Universidad Metropolitana de Barranquilla, Colombia. Adscrita a la línea de investigación "EDUSAR", código del grupo: COLO165256. Correo electrónico: faraque@unimetro.edu.co

3 Especialista en Administración y Docencia Universitaria. Diplomado en Pedagogía y Mediaciones Tecnológicas. Fisioterapeuta. Docente y Coordinadora de prácticas estudiantiles de la Universidad Metropolitana de Barranquilla, Colombia. Correo electrónico: Mery.cunha@unimetro.edu.co 


\section{INTRODUCCIÓN}

En los últimos años el tema de la discapacidad, concretamente su definición y estudio, ha conllevado numerosos debates que han tomado diferentes aristas en su abordaje: calidad de vida, inclusión social, igualdad, marginación, diferencia, entre otros.

Lo cierto es que resulta relevante el cambio que ha tenido la concepción de la discapacidad como elemento anómalo para ser asumida desde una visión más humanista e integrativa, son múltiples las acciones de las comunidades conformadas por personas con discapacidad y el esfuerzo de los organismos internacionales y nacionales en superar los lastres ideológicos, históricos y sociales que circulan en el imaginario colectivo relacionados con la percepción y reincorporación en la vida social de las personas discapacitadas.

De este modo, hablar de familias con miembros discapacitados es hablar de diversidad, si bien con el progresivo desarrollo de la sociedad, ésta ha ido cediendo terreno a las funciones educativas, parece insustituible en los procesos formativos primarios relacionados con los sentimientos, actitudes, valores y la asimilación e interiorización de pautas sociales.

En efecto, el ser humano como actor social aprende en su núcleo familiar y comunitario la mayoría de los comportamientos y la forma de ver el mundo.

Desde un punto de vista cultural la familia para Vidal (2000), es la agrupación humana por naturaleza que estructura lo social y lo cultural; el lugar donde se afianza las creencias, los valores cognitivos y lo normativo entrelazado en un solo proceso que trenza las tres legitimaciones y las enraíza en la propia definición de la identidad del sujeto en formación. Como institución central de los procesos de integración social, efectúa no solo la socialización primaria de los hijos, sino que también establece marcos en los que se configuran los sistemas de interacción y de construcción de identidades de los adultos.

La familia genera y trasmite la forma básica de valor moral: las maneras de vinculación social desde la igualdad y la inclusión de los otros.

En efecto, muchos teóricos han explicado cada vez más el estudio de la familia desde el micro-análisis; siendo las principales áreas de investigación las siguientes: desarrollo, satisfacción y disolución de relaciones íntimas, satisfacción y estabilidad de las relaciones maritales, divorcio y separación conyugal, violencia intrafamiliar (Gracias Musitu, 2002). Hasta las investigaciones y disertaciones de las familias con miembros en condiciones 
de discapacidad (Verdugo y Shalock, 2010), siendo el objetivo final lograr una mejor calidad de vida.

Es evidente, que estos temas tratados son expresión emergente de los procesos macro-sociales del desarrollo y funcionamiento contemporáneo de la familia en la actualidad.

Dentro de esta nueva realidad, el reconocimiento de las familias en el desarrollo de sus miembros, es una de las razones primordiales del aumento del interés por consensuar esfuerzos institucionales para su atención y fortalecimiento (Manjarres, León y otros; 2013).

El informe mundial de discapacidad de la Organización Mundial de la Salud, publicado en 2011, estima que el 15\% de la población mundial vive con algún tipo de discapacidad. En Colombia de acuerdo al Censo de 2005, la prevalencia es de alrededor de 6.3\% correspondiendo a 2.624.898 de personas para ese momento, con una distribución por sexo de $6,5 \%$ de hombres y $6,1 \%$ de mujeres.

En líneas generales, la sociedad ha ido tomando conciencia y acciones en la mejora de los procesos de inserción social cada día más (Gómez, 2007). A este respecto, la aceptación de la diversidad y heterogeneidad actúan convergentemente, y orienta la acción común al desarrollo de estrategias de inclusión, comprensión y equilibrio como régimen propio de la vida en sociedad.

Con relación a estos avances, la ley 1618 del 2013 señala: "se establecen disposiciones para garantizar el pleno ejercicio de los derechos de las personas discapacitadas". Sin duda el Estado Colombiano busca garantizar y asegurar el ejercicio efectivo de los derechos de las personas con discapacidad mediante la adopción de medidas y políticas que cuenten con enfoque de inclusión, lo que permitirá eliminar toda forma de discriminación dada por una condición.

Dicha ley dicta medidas específicas para garantizar los derechos de los niños y las niñas con discapacidad; el acompañamiento a las familias; el derecho a la habilitación y rehabilitación; a la salud; a la educación; a la protección social; al trabajo; al acceso y accesibilidad; al transporte; a la vivienda; a la cultura; el acceso a la justicia; entre otros. Una nueva ley busca garantizar el cumplimiento de las anteriores, ya que según la ley 1752 se determina penalizar la discriminación a personas discapacitadas. Esta nueva ley está en correlación con la Convención sobre los derechos de las personas con discapacidad de Naciones Unidas, ley 1346 de 2009, que define discriminación por motivos de discapacidad en el artículo № 2 así: "cual- 
quier distinción, exclusión o restricción por motivos de discapacidad que tenga el propósito o el efecto de obstaculizar o dejar sin efecto el reconocimiento, goce o ejercicio, en igualdad de condiciones, de todos los derechos humanos y libertades fundamentales en los ámbitos políticos, económicos, sociales, culturales, civil o de otro tipo. Incluye todas las formas de discriminación, entre ellas, la de negación de ajustes razonables" p. 68

Con la ley 1752 de 2015, el Código Penal tiene un artículo 134ª que determina que el que arbitrariamente impida, obstruya o restrinja el pleno ejercicio de los derechos de las personas por razón de discapacidad, incurrirá en prisión de 12 a 36 meses y multas de 10 a 15 salarios mínimos legales mensuales vigentes.

De igual manera incorporo al Código Penal el artículo 134b, que sanciona el hostigamiento por razón de discapacidad, determinando que el que promueva o instigue actos, conductas o comportamientos constitutivos de hostigamiento, orientados a causarle daño físico o moral a una persona, grupo de persona, comunidad o pueblo, por razón de discapacidad, incurrirá en prisión de 12 a 36 meses y multa de 10 a 15 salarios mínimos legales mensuales vigentes.

En consecuencia, la discriminación y el hostigamiento por razón de discapacidad constituyen dos nuevos delitos en Colombia. Tipificados con pena privativa de libertad y con multas en base a los salarios vigentes.

Es obvio, que la realidad ha ido mejorando a favor de las personas discapacitadas, no obstante, esto no solo debe ser letra muerta, lo importante es el compromiso adquirido por todos los actores sociales propulsores de la inclusión social.

Es menester, promover no solo desde el Código Penal una sociedad más justa e igualitaria, sino también realizar esfuerzos con nuevas iniciativas educativas que construya una ética de la responsabilidad para articular las Universidades en la construcción de un tejido de valores compartidos y comunes.

Se sugiere, superar la obligación legal desde la imposición para promover la responsabilización, como capacidad ejercida de manera voluntaria y consensuada de todos los actores sociales implicados en el proceso, para aportar soluciones a la vida social y la posibilidad de una vida más humana.

Según el estudio, una de las maneras de dar respuesta a esta demanda es por medio de los procesos de intervención en salud a partir de las prácticas formativas de los estudiantes universitarios y su contribución en escenarios comunitarios, como en el caso de los centros pilotos de la Cui- 
dad de Barranquilla, específicamente el Centro educativo de habilitación y rehabilitación San Camilo.

La Organización Mundial de la Salud (2013) define la Evaluación del Impacto en la Salud (EIS): como una combinación de procedimientos, métodos y herramientas a través de las cuales se puede juzgar una política, programa o proyecto en relación a sus efectos potenciales sobre la salud de la población y la distribución de estos.

Todo esto demanda que las tendencias y políticas educativas orientan a las Instituciones de Educación Superior (IES), asumir un nuevo paradigma, que permita la formación integral del individuo y que a su vez contribuya al mejoramiento de las condiciones de vida del entorno.

El seguimiento de la práctica, a través de estudios formales, se convierte entonces en un aspecto de vital importancia para las universidades, ya que las actividades realizadas en las prácticas formativas en el medio social, van relacionadas directamente con los aportes en torno a la calidad de vida de la población intervenida.

Se indica así mismo, que varios serían los beneficios obtenidos a partir del producto de dicha investigación, por un lado el conocimiento de cómo se están llevando a cabo las prácticas, lo que le permite a la Universidad Metropolitana verificar el cumplimiento de su función social, por otro lado dichos resultados retroalimentan el currículo de formación de sus estudiantes de manera que se ajuste a la necesidades reales del medio y finalmente el impacto positivo dentro de las comunidades atendidas.

Para concluir es importante destacar que esta investigación de tipo descriptiva busca identificar y describir los cambios producidos en la comunidad asistida en los Centros Pilotos, escenario donde se desarrollan las prácticas formativas de los estudiantes de la Universidad Metropolitana de Barranquilla.

\section{REFLEXIONES TEÓRICAS}

\section{Algunas cuestiones generales con respecto a la discapacidad}

En la antigüedad la discapacidad era asumida como una "anormalidad" producto del castigo divino a consecuencia de los pecados. El individuo al no poderse valer por sí mismo, ni lograr realizar las actividades necesarias para su subsistencia, se consideraban una carga para el colectivo, siendo en muchos casos asesinado, encerrados o marginados. Por ejemplo, en la Esparta del siglo IX a.C. las leyes de Licurgo dictaminaban que los nacidos deformes o débiles fueran arrojados desde lo alto del monte Taigeto 
(Inzua, 2001).

A este modelo inicial se le reconoce como el de Prescindencia, en efecto, este modelo se explica a partir de dos postulados, uno relacionado con la causa de la discapacidad y otro con el rol del discapacitado en la sociedad (Palacios, 2008).

Respecto del primero, propone que las causas que daban origen a la discapacidad eran religiosas. En cuanto al segundo, identificaba el rol de la persona con su utilidad, partía de la idea de que el discapacitado no tenía nada que aportar a la sociedad, que era un ser improductivo y, por consiguiente, terminaba transformándose en una carga tanto para sus padres como para la misma comunidad.

Según Palacios, a su vez surgieron dos consecuencias que dieron origen a dos sub-modelos: el eugenésico y el de marginación. Así, si bien desde ambos sub-modelos se prescindía de las vidas de los infantes discapacitados, en el primero (característico del mundo griego), la solución estaba enfocada hacia la eliminación del niño dándole muerte; mientras que en el segundo (puesto en práctica con la introducción y expansión del cristianismo) dicho objetivo se alcanzaba mediante la separación o el alejamiento del recién nacido del núcleo social.

Posteriormente, la ideología cristina influye en mejor las condiciones de trato a los ciegos, paralíticos, sordos, mudos, ente otros. Es a partir del siglo XVIII cuando la sociedad comienza a entender su responsabilidad, hacia los seres humanos más vulnerables tanto física como mentalmente.

Posteriormente aparece el modelo rehabilitador donde según (Palacios, 2008), las causas que originan la discapacidad ya no son religiosas, sino científicas. Dejando de ser una carga para la sociedad, siempre y cuando sean rehabilitadas psíquica, física o sensorialmente, a fin de eliminar la diferencia existente. De manera que el sujeto puede ser integrado a la sociedad y ser productivo. La consolidación de este modelo en el ámbito legislativo se ubica en el siglo XX, aunque sus inicios se remontan a los inicios del mundo moderno.

Su impacto más importante viene de la clasificación de la discapacidad basada en la percepción médica, por lo que todo programa o política referente a la "integración" educativa, laboral, social, etc., estaban transversalizadas o regidas por estas clasificaciones de tipo médico, desconociendo otras áreas de atención y del desarrollo de este colectivo.

Un tercer modelo, el Modelo Social, considera que las causas que ocasionan la discapacidad no son religiosas ni científicas, sino que son en 
gran medida sociales. Desde esta filosofía "...se insiste en que las personas con discapacidad pueden aportar a la sociedad en igual medida que el resto de personas — sin discapacidad, pero siempre desde la valoración y el respeto de la diferencia" (Palacios, 2008).

Este modelo se encuentra mediado por los derechos humanos, y espera potenciar el respeto por la libertad, igualdad y la inclusión social, y fundamentándose en la no exclusión, la otredad, la vida independiente, el dialogo, entre otros.

Este modelo actualmente aceptado e implantado internacionalmente dio pie para la aparición de un cuarto modelo, denominado de la Diversidad funcional. Este toma los elementos del modelo social, pero incorpora aspectos como el reconocimiento y restablecimiento de la dignidad, la accesibilidad para todos como diseño universal, el uso de la bioética como elemento fundamental del cambio, propende por la autonomía de la persona con discapacidad para decidir respecto de su propia vida y remarca la igualdad y respeto por la discapacidad, o como lo denomina este modelo: la diversidad funcional.

Para Palacios y Romañach (2005), la diversidad funcional es definida como algo inherente al ser humano, puede ser de carácter transitorio o circunstancial. Es decir, de forma directa, indirecta, transitoria o definitiva, toca a los seres humanos.

Esta se ajusta a una realidad en la que una persona funciona de manera diferente o diversa de la mayoría de la sociedad. No tiene nada que ver con la enfermedad, la deficiencia, la parálisis, el retraso, etc.

Gracias a esta evolución conceptual, se forma un quiebre con la tradición ideológica, que ha tenido que ver con la definición de la discapacidad como una limitación o un obstáculo a consecuencia de un castigo divino o extranatural.

De hecho, en las tres últimas décadas la discapacidad ha tenido un viraje como una condición que debe ser asumida con una visión ecológica y humanista (Buntinx 2013). Tomando en cuenta todas las dimensiones de las personas que tienen esta condición, desde las emocionales, ideológicas, económicas, hasta las ambientales.

Según la Organización Mundial de la Salud, más de mil millones de personas tienen alguna forma de discapacidad es decir el 15\% de la población mundial y entre 110 y 190 millones de personas adultas tienen dificultades para funcionar. Esta puede ser muy diversas. 
Al ubicarse, en Colombia el censo general de la población, señala que el número de personas con discapacidad en el país es de aproximadamente 2.640.000 (Departamento Administrativo Nacional de estadística, 2006). Es decir, por cada 100 colombianos 6.3 tienen limitaciones permanentes, por lo que se reclaman políticas puntuales por y para esta población.

La Organización Mundial de la Salud (OMS), delimitó el significado y tipos de: deficiencia, discapacidad y minusvalía, a partir de la necesidad de considerar no solo la enfermedad sino las consecuencias de ésta en todos los aspectos de la vida de la persona, ampliando la concepción inicial basada exclusivamente en el modelo médico. Señala el siguiente esquema:

- Discapacidad: Restricción o ausencia (debida a una deficiencia) de la capacidad de realizar una actividad en la forma o dentro del margen que se considera normal para un ser humano.

- Minusvalía: Situación desventajosa para un individuo determinado, consecuencia de una deficiencia o de una discapacidad, que limita o impide el desempeño de un rol que es normal en su caso, en función de su edad, sexo, factores sociales y culturales.

- Deficiencia: Pérdida o anormalidad de una estructura o función psicológica, fisiológica o anatómica.

Por consiguiente, la discapacidad, es un fenómeno complejo que refleja interacción entre las características del organismo humano y las características de la sociedad en la que vive. Es un término que abarca las deficiencias, las limitaciones de la actividad diaria y las restricciones de la participación. Las deficiencias son problemas que afectan a una estructura o función corporal; las limitaciones de la actividad son dificultades para ejecutar acciones o tareas y, las restricciones de la participación son limitantes en situaciones vitales.

En este contexto, la participación de todos los actores sociales es fundamental. Una acción educativa fundada en la responsabilidad ética de las Universidades en Colombia puede promover una sociedad del saber, que oriente al conocimiento al desarrollo de estrategias de inclusión social, comprensión común y equilibrio social. De este modo el saber orienta la convivencia como régimen propio de la vida de las sociedades. Impulsar una educación centrada en el respeto, la prudencia, la justicia, la fortaleza y la templanza para la construcción de una trama que permita la convivencia en la diversidad (Cortina, 2005).

De allí, la importancia de los procesos de intervención en salud desde las prácticas formativas de los estudiantes de la Universidad Metropolitana, 
tales como: medicina, optometría, fisioterapia, terapia ocupacional, fisioterapia, nutrición y dietética, enfermería, fonoaudiología, bacteriología, psicología, trabajo social.

Es importante, destacar que una acción educativa fundada en la responsabilidad ética puede hacerse desde la Universidad como expresión de la materialización de la Proyección Social, expresada en el vínculo de la Universidad con la sociedad mediante procesos permanentes e interdisciplinarios que integran la docencia y la investigación para contribuir a la búsqueda de soluciones a los problemas encontrados y a la formación del estudiante.

\section{Prácticas Formativas de la Universidad Metropolitana}

En efecto, desde 1992, como respuesta al Plan de desarrollo 19861990 de la Universidad Metropolitana, se creó la oficina de prácticas extramurales centralizando los denominados programas de extensión, cuyo objetivo principal era prestar eficientes servicios de salud integral para el bienestar físico, mental y social de la familia y la comunidad.

En ese mismo año, en el desarrollo de las prácticas formativas, se consideraban dos elementos importantes con características diferentes como son la integración docente asistencial y los denominados Centros Pilotos, con la finalidad de coordinar las acciones de la proyección de la institución hacia la comunidad, la planificación, supervisión y asesoría de la integración docente asistencial, la investigación y la extensión, apoyándose en el trabajo interdisciplinario y centrándose en objetivos comunes.

Es así como, partiendo de la necesidad del entorno sean especificados características poblacionales, sociales, económicas, laborales y de salud.

En efecto, se han realizado diferentes intervenciones tales como mejorar la funcionalidad de los niños en situación de discapacidad, a través del uso de los diferentes tipos de ortesis, talleres vocacionales de formación para el trabajo en los jóvenes, programa de rehabilitación para el adulto mayor, programa de promoción y prevención en salud oral, programa escuela para padres, jornadas de salud en fisioterapia, terapia ocupacional, fonoaudiología, psicología, nutrición, enfermería, trabajo social y bacteriología e implementación del sistema pictográfico como alternativa de comunicación para niños con trastornos neuromotor, entre otros.

La finalidad, es lograr el máximo desarrollo de todos los actores sociales implicados en este proceso. 
En, la perspectiva asumida, esta investigación rompe con la separación establecida entre el conocimiento científico y los saberes comunes, puesto que socializa lo que proviene de la ciencia e incorpora los que aportan las comunidades. De esta manera se enriquecen ambos campos y produce nuevos conocimientos alimentados por las dos vertientes portadoras de saberes juzgados por ambos tipos de actores sociales, por la especialidad profesional de los agentes de la Universidad Metropolitana y por el conocimiento histórico y culturalmente producido en las comunidades a las cuales pertenecen los lideres o representantes internos.

Dentro de este conjunto el plan de estudios de cada Programa Académico creo estos espacios de prácticas para el estudiante con la orientación científica de los docentes, fomentando las actividades de Extensión, Docencia e Investigación. Dentro de este marco de acción la Universidad responde a los problemas que presenta un contexto determinado impulsando el desarrollo que requiere la localidad en la cual está inmersa, creando a su vez aportes científicos en las diversas disciplinas que participan de esta actividad.

La práctica universitaria estudiantil se considera como el punto de encuentro entre el currículo de formación y la realidad social. Se constituye en la base para el desarrollo de las competencias profesionales en términos del saber, saber hacer y del ser y en el elemento que permite la vivencia armónica de la extensión, la investigación y la docencia.

Su propósito consiste en la aplicación directa de todos los conocimientos teóricos y prácticos adquiridos para que al momento de problematizar las necesidades específicas de la comunidad ya sean en forma individual o colectiva, cumpla con los requerimientos de la disciplina de tal manera que en el ejercicio de la misma los estudiantes se proyectan a la sociedad en forma competente, ética y humanística unificando el trabajo social y comunitario con el proceso de aprendizaje.

Para el desarrollo de las prácticas se han determinado unos escenarios, entendiéndose por este como ese espacio geográfico donde se aplican procesos de intervención intencionalmente planificados por parte de un equipo coordinador interinstitucional, de docentes asignados para esta función y los estudiantes que les compete este ejercicio, en las realidades sociales específicas de los contextos que se seleccionan para las prácticas, según convenio ICFES y Universidad del Valle (1997).

Tal es el caso de las actividades realizadas en los Centros Pilotos consideradas como una estrategia académica-administrativa que utiliza la Uni- 
versidad Metropolitana para orientar al recurso humano desde las prácticas de proyección social de la Institución con el fin de promover la organización de las actividades de promoción de salud y prevención de enfermedades, asistenciales, de rehabilitación e investigación dentro de la comunidad. Entre los centros pilotos se encuentra Ce Camilo el cual tiene sus raíces en un programa para niños desnutridos y desarrollo comunitario que María Poulisse de los Religiosos Camilos organizó en 1985 con apoyo de un grupo de voluntarias del barrio la Paz y con financiación de Caritas Neerlandica.

En enero de 1994 se organizó un día especial en un local en la Cra. 13 No. 104-52 del barrio la Paz para la recuperación de niños desnutridos y se detectaron niños con discapacidad y estado de minusvalía, es por ello, que a partir de estas evidencias se recibieron niños con discapacidad severa para que sus madres pudieran trabajar realizándoles rehabilitación y terapia.

Entre 1998 y 2008 se construyó la infraestructura del Centro Ce Camilo siendo la población beneficiaria niños y jóvenes con retraso en el desarrollo psicomotor, entre los 2 y los 25 años de edad, identificando los siguientes perfiles: lesión neurológica, retardo mental, autismo y problemas de aprendizaje.

Esta población excluida de muchas oportunidades sociales y en muchos casos estigmatizados y en situación de abandono, fue censada en el 2010.

Posteriormente, en el 2012 y 2013, este Centro Piloto recibió aportes por parte de la Alcaldía Distrital de Barranquilla para la atención integral de la discapacidad, de manera que el Estado Colombiano intervino con políticas públicas a nivel nacional a fin de mejorar la calidad de vida y garantizar el derecho de inclusión a personas en situación de discapacidad de estrato uno (1) de Barranquilla. Colombia.

Actualmente, este Centro Piloto atiende a más de 280 niños y jóvenes con diferentes clases de discapacidades, y también presta atención en salud a 200 pacientes ambulatorios aproximadamente.

Los programas de intervención en salud que se realizan en este centro piloto se caracterizan por desarrollar las capacidades de los usuarios atendidos, la participación de la familia y el compromiso con la comunidad de los sectores que asisten a él.

Atendiendo a estas consideraciones, y para lograr una atención más eficaz desde el empoderamiento de la misma comunidad, se plantea realizar el abordaje investigativo desde la participación activa de los agentes internos y externos implicados en el proceso. Este proyecto tiene una orien- 
tación a la transformación social, así como un carácter crítico, dialógico, reflexivo, político, fortalecedor de la sociedad civil, además este tipo de investigación es colectiva y, en Latinoamérica, no se le utiliza sólo para constatar, sino también para problematizar la realidad.

Esta es otra forma de contribuir a disminuir la pobreza y exclusión en América Latina, de hecho, según la investigadora Juliana Londoño, quien ha auscultado el tema en cuestión y cursa un doctorado en economía en la Universidad de Berkeley. Sostiene que, a pesar de que el indicador de la desigualdad no ha bajado, Colombia sí ha venido avanzando en el empoderamiento de los sectores de escasos recursos económicos. Londoño exalta los programas de transferencias condicionadas, como unas de las herramientas redistributivas más poderosas que tiene el Estado.

Es importante, recordar que un miembro con discapacidad bien sea de nacimiento o adquirida, está sometido a condiciones de impotencia, tristeza, exclusión emocional, económica y laboral, con menos posibilidades de autonomía.

De allí, que es menester profundizar en el tema y afrontarlo para convertirlo en una oportunidad de crecimiento individual y colectiva.

\section{Una mirada a la inclusión de la discapacidad desde los procesos de intervención en salud}

Aunque el ser humano tiene una tendencia natural a vivir en comunidad, la convivencia social es construida, mediada por una serie de aprendizajes básicos: comunicación, resolución de conflictos, intereses personales y comunitarios, bienestar físico y psicológico, sentido de pertenencia con la naturaleza, entre otros. La sociedad es una expresión maravillosa de la heterogeneidad del ser, ese convivir diario está compuesto de la diferencia y la diversidad. Denominada desde lo académico heterogeneidad, impregnada por la diversidad y las caracterizaciones particulares. Es sencillamente el convivir diario. Esta diversidad exige un compromiso por parte de diferentes partes para la sana convivencia, así como el respeto y reconocimiento de su diferencia en la igualdad, entre otros, que permitan más que una integración, una inclusión total.

Si se pretende buscar el significado de "Incluir" se encontrará definida como: "abarcar, contener en sí, Involucrar, implicar, insertar, intercalar, introducir, hacer parte, figurar entre otros, pertenecer conjuntamente con otros..." (Adirón 2005).

Según el estudio, presenta varios significados, todos ellos con el sentido de algo o alguien insertado entre otras cosas o personas. Esta definición 
no reconoce que el ser incluido requiere ser igual o semejante a los demás.

Visto desde la perspectiva del estudio, cuando se habla de la inclusión social, la primera idea que pensamos es la capacidad que tenemos como ser humano de valorizar la diversidad humana

Pero cuando se habla de una sociedad inclusiva, se piensa en valorizar la diversidad humana y fortalece la aceptación de las diferencias individuales. Es dentro de ella, que se aprende a "convivir y contribuir juntos un mundo de oportunidades reales (no obligatoriamente iguales) para todos". (Adirón, 2005).

Esto implica una sociedad en donde cada uno es responsable por la calidad de vida del otro, aun cuando ese otro es muy diferente de nosotros.

Atendiendo a estas consideraciones, el concepto de inclusión es amplio pretendiendo disminuir todas las barreras al aprendizaje y a la participación. Porque somos asimismo seres orientados a la trascendencia, que busca darle sentido a una existencia, que persiguen trascender su propio existir.

Por su parte, (Lakoff y Johnson, 1995), plantean que es fundamental darse cuenta de que la forma de percibir nuestro mundo, no es la única, y que es necesario abrirse a ver más allá de las verdades impuestas por nuestra cultura o por nuestro imaginario colectivo.

Es por ello, que somos seres en permanente construcción desde los espacios micros que vivimos como la familia hasta los espacios de construcción de un tejido de valores compartidos y comunes (Martin, 2007).

En este marco, la Universidad en su conjunto debe aportar soluciones a la vida social; promover la responsabilidad social anticipadamente, entendida como la obligación moral de vincularse con las comunidades.

En efecto, con la mirada puesta en la realización del bien común, es fundamental que las organizaciones educativas asuman un proceso de construcción de eticidad, al saber que el deber ser es un proceso de elaboración permanente en la construcción de eticidad.

Los procesos de intervención en salud llevados a cabo por los diferentes programas académicos de la Universidad Metropolitana durante el periodo en estudio, han sido los siguientes:

\section{Universidad Metropolitana}

Extensión y Proyección Social

Programas y Proyectos de Intervención en Salud.

En el 2009 se realizan los programas y proyectos de intervención en salud, para aplicarse por medio de las prácticas formativas en el Centro Piloto Ce Camilo, intervienen Fisioterapia, Trabajo Social, Nutrición, Terapia 
Ocupacional y Fonoaudiología, se elaboraron los documentos y propuesta a desarrollar en los usuarios.

En efecto, los procesos de intervención realizados son los siguientes:

Fecha: 2009 - 2016.

Programa de atención integral a la familia

Objetivos: Identificar las deficiencias funcionales y/o limitaciones en la actividad diaria y restricciones en la participación para la emisión de un diagnóstico.

Aplicar métodos de tratamiento acorde a las necesidades y evolución de los usuarios.

Aplicar métodos de tratamiento grupal coherente a las necesidades y evolución de los usuarios.

Prácticas de formación participantes: Fisioterapia, Trabajo Social, Nutrición, Terapia Ocupacional y Fonoaudiología.

Actividades: Observación clínica, aplicación de las entrevistas inicial, valorización y aplicación de pruebas psicométricas, atención individual, evaluación, diagnostico e intervención para el manejo de las alteraciones del sistema neuromuscular, atención en piscina, diligenciamiento de historia nutricional, actualización de datos antropométricos, diagnostico nutricional Ce Camilo, hogares comunitarios, infantil y Fami, detención temprano de los desórdenes comunicativos y lingüísticos, intervención habla y lenguaje, evaluación e intervención para el desarrollo de las habilidades motoras finas y el autocuidado, abordaje grupal para la aplicación de métodos de tratamiento en psicología, estimulación del lenguaje y adquisición de habilidades lúdicas, sociales y escolares necesarias para el aprendizaje.

Beneficiarios: niños, niñas y jóvenes con discapacidades

Fecha: 2009 - 2016.

Programa de educación para el trabajo y desarrollo humano.

Objetivos: brindar atención educativa de calidad para el logro de las potencialidades individuales que contribuyan al progreso en su contexto social.

Prácticas de formación participantes: Psicología, Trabajo Social, Terapia Ocupacional y Fonoaudiología.

Actividades: taller de autocuidado con los diferentes grupos, desarrollo de habilidades sociales, adiestramiento a los operarios del taller de panadería sobre las normas establecidas, orientación sobre aspectos ergonómicos para la manipulación de máquinas, visitas domiciliarias e intervención del grupo familiar, atención grupal de habilidades comunicativas, 
elaboración y entrega del perfil profesional de los jóvenes de los talleres de madera, modistería, panadería y pintura.

Beneficiarios: jóvenes.

Fecha: 2009 - 2016.

Programa educativo escuela de familia, capacitación, detención de alteraciones y promoción de la salud.

Objetivos: promover hábitos de vida favorable en los padres de familia que favorezcan un ambiente familiar de calidad, mejorar las condiciones en el área de cocina y panadería, detectar las alteraciones del lenguaje y comunicación, nutrición, motricidad fina y parasitosis, orientar a los niños y niñas sobre el cuidado de la salud y conservación de la misma.

Prácticas de formación participantes: Nutrición, Psicología, Fonoaudiología, Trabajo Social, Terapia Ocupacional, Fisioterapia, Fonoaudiología y Bacteriología.

Actividades: Charlas y talleres de dinámica familiar, orientación en la atención y cuidados a padres y cuidadores de personas discapacitadas, talleres a las familias sobre comunicación adecuada, manejo de autoridad, moldear conductas erróneas de sus miembros a fin de generar mejor calidad de vida de los adolescentes, capacitación personal a los manipuladores de alimentos, capacitaciones en medidas de higiene, exámenes de laboratorios, educación nutricional, vigilancia epidemiológica, ostoscopias, barrido del lenguaje, evaluación del desarrollo, actividades lúdica, higiene corporal, prevención del abuso sexual y prevención de bulling.

Beneficiarios: padres, madres o cuidadores.

Fecha: 2009 - 2016.

Programa de seguridad alimentaria y nutricional.

Objetivos: valorar el estado nutricional de la población que asiste a las instituciones Ce Camilo, hogar comunitario, hogar infantil, evaluar la BPM en el servicio de alimentación y panadería.

Prácticas de formación participantes: Nutrición y Bacteriología.

Actividades: diligenciamiento de historia nutricional, valorización, verificar condiciones de salud del personal de panadería y cocina, realizar exámenes, supervisar las buenas condiciones de los alimentos y de la planta física, control de temperatura, manejo y control adecuado de alimentos, preparación de alimentos y manejo de residuos sólidos.

Beneficiarios: usuarios externos de la institución.

Fecha: 2012 - 2016.

Programa de rehabilitación basado en la Comunidad. 
Objetivos: fortalecer y ampliar las actividades del proyecto de rehabilitación con la comunidad para mejor la calidad de vida de las personas con discapacidad y su familia.

\section{Caracterización de las familias atendidas}

Prácticas de formación participantes: nutrición, fisioterapia, fonoaudiología, trabajo social, terapia ocupacional y psicología.

Actividades: participación en el campeonato del bebe sano, atención a las comunidades de los sectores de la paz, el bosque, 7 de abril, chinita, olivo, lipaya y rebolo de la Cuidad de Barranquilla en Colombia.

Beneficiarios: comunidad de los diferentes barrios en Barranquilla.

Fecha: 2012 - 2016.

Programa de asistencia tecnológica.

Objetivos: orientación y realización por parte de los estudiantes de ortesis, según necesidades de los niños atendidos. cional.

Prácticas de formación participantes: fisioterapia y terapia ocupa-

Actividades: dotación, adiestramiento y usos de asientos pélvicos, férula de manos y bipedestadores.

Beneficiarios: niños, niñas, adolescentes y adultos.

Fecha: 2012 - 2016.

Programa de asistencia tecnológica.

Objetivos: orientación y realización por parte de los estudiantes de ortesis, según necesidades de los niños atendidos. cional.

Prácticas de formación participantes: fisioterapia y terapia ocupa-

Actividades: dotación, adiestramiento y usos de asientos pélvicos, férula de manos y bipedestadores.

Beneficiarios: niños, niñas, adolescentes y adultos.

Fecha: 2009 - 2010.

Programa de asistencia tecnológica.

Objetivos: desarrollar las habilidades de interacción y de comunicación con niños y niñas con trastornos neuromotor, desarrollar el rol de la familia con la implementación del sistema pictográfico en la Fundación $\mathrm{Ce}$ Camilo.

Prácticas de formación participantes: fisioterapia, fonoaudiología y terapia ocupacional.

Actividades: dotación, adiestramiento y usos de tableros pictográficos y poster. 
Beneficiarios: niños, niñas, adolescentes.

Fecha: 2013 - 2014.

Programa de asistencia tecnológica.

Objetivos: caracterización de la población usuaria atendida en la Fundación Ce Camilo, con el propósito de diseñar ayudas tecnológicas como estrategias de apoyo a procesos de rehabilitación en la Cuidad de Barranquilla.

Prácticas de formación participantes: fisioterapia, fonoaudiología y terapia ocupacional.

Actividades: seminarios de actualización en el uso de la tecnología, adaptaciones para alimentos, taller de ortesis, uso de asientos pélvicos.

Beneficiarios: niños, niñas, adolescente.

\section{MATERIALES Y MÉTODOS}

Este artículo es el producto inicial de una investigación cualitativa y descriptiva, dado que los procesos de intervención en salud serán descritos a partir de su ejecución por medio de las prácticas formativas llevadas a cabo por los estudiantes en el Centro piloto Ce Camilo.

Es también, relevante su carácter cualitativo, tal como señalan Strauss y Corbin (1990), el carácter cualitativo está dado por los resultados a los que no se ha llegado por procedimientos estadísticos u otro tipo de cuantificación. Puede referirse a investigaciones acerca de la vida de las personas, comportamientos, historias, y también al funcionamiento organizativo, movimientos sociales o relaciones e interacciones. Algunos de los datos pueden ser cuantitativos pero el análisis en sí mismo es cualitativo.

Este tipo de investigación constituye en la actualidad un concepto amplio que hace referencia a diversas perspectivas epistemológicas y teóricas, incluyendo también diferentes métodos y estrategias de investigación.

En este sentido Colas (1997), plantea que los objetivos de tipo descriptivos en este tipo, de investigación identifica elementos, explora sus conexiones y describe procesos, contextos, instituciones, sistemas y personas como es el caso del estudio.

Como estrategias de recolección de la información se utilizó la observación participante y el fichaje, revisión y análisis de los registros existentes sobre las prácticas formativas de los estudiantes de la Universidad Metropolitana de Barranquilla, llevadas a cabo en el Centro de habilitación y rehabilitación Ce Camilo en la atención de los usuarios en condiciones de discapacidad. 


\section{CONCLUSIONES}

En la Constitución de la República de Colombia (1991) se exige de la acción pública la promoción, reconocimiento, garantía y restitución de los derechos fundamentales, civiles políticos, económicos, culturales, sociales y colectivos de todos los habitantes del país sin distinción de etnia, culto o creencia, género o condición socioeconómica, con especial atención hacia los niños, niñas, jóvenes, personas mayores y en condición especial de discapacidad.

La experiencia ha demostrado que el abordaje social desde las instituciones Universitarias debe contener la evaluación social, la intervención y el seguimiento y a esa realidad se enfoca este estudio. Aunque la fase de intervención es la acción propiamente dicha, el seguimiento es muy importante, al llevar registro de las metas alcanzadas se pueden realizar diagnósticos sociales, y actualizar los instrumentos de recolección de datos evitando la rigidez y permanencia estática en el tiempo.

La conexión Universidad y Comunidad por medio de los procesos de intervención sociales es una condición que juega un gran papel en el fortalecimiento de los procesos

Comunitarios inclusivos, que favorece la construcción de sujetos con respeto, solidaridad y responsabilidad.

Esto en relación a los derechos de las personas con discapacidad, por estar expuestas a situaciones de discriminación y exclusión, la intervención social comunitaria e intra-institucional potencia el desarrollo de sus derechos fundamentales, buscando la plena participación y su pleno desarrollo integral.

Finalmente, los equipos multidisciplinarios en el campo de la salud producen una mejor calidad de vida, fortalece la diversidad y el pluralismo de la sociedad civil y favorece el desarrollo de nuevos actores y movimientos sociales, entendiendo que una sociedad se enriquece y se hace más sustentable mientas más se expresen las distintas miradas y aproximaciones que frente a una misma realidad tienen las personas.

\section{REFERENCIAS BIBLIOGRÁFICAS}

Adirón, F. (2005) ¿Qué es la inclusión?: La diversidad como valor. Moderador del grupo de discusión electrónica sobre síndrome de Down. Brasil. Whemeyer. Edi. The Oxford handbook of positive psychology and disabilty (pp.7-18). New York. Oxford University press.

Buntinx, W. (2013). Understanding disability: a strengths-based approach. In

Cortina, A. (2005). Educación en valores y responsabilidad cívica. Editorial el Buho. 
Bogotá. Colombia.

Colas, M. (1997). Métodos y técnicas cualitativas de investigación en psicopedagogía. En L Buendía, M. P. Colás y F. Hernández (Eds.). Editorial McGraw Hill.

Derechos de las personas con discapacidad. (2010) Derechos de las personas con Discapacidad. México. Tomado de: http://www.cedhj.org.mx/derechos_humanos/cuales_son/discapacidad.html

Gómez, E. (2007). Familias multiproblemáticas y en riesgo social: característica e intervención. Revista PSYKHE. Vol. 16. № 2. Pág. 43-54. Chile.

Gracias, E. y Musitu, G. (2002). Psicología social de la familia. Editorial Pairos. Ibérica. España.

Inzua, V. (2001). "Una conciencia histórica y la discapacidad". Revista de Trabajo Social Nueva Época. Número 3. México.

Lakoff, G y Johnson, M. (1995). Metáforas de la vida cotidiana. Editorial Teoremas. Madrid. España.

Ley Estatuaria 1618 del 2013. República de Colombia. Derechos de las personas con Discapacidad. Tomado de: http://wsp.presidencia.gov.co/Normativa/Leyes/Documents/2013/LEY\%201618\%20DEL\%2027\%20DE\%2OFEBRERO\%20 DE\%202013.pdf

Martin, V. (2007). Ética, educación y construcción de convivencia. Revista educación en valores. Universidad de Carabobo. Julio-Diciembre. Vol. 2. No 8

Manjarres, D. y otros (2013). Crianza y discapacidad: una visión desde las vivencias y los relatos de las familias en varios lugares de Colombia. Universidad Pedagógica Nacional. Tomado de: htpp://www.colombiaaprende.edu.co/html/ micrositios/1752/articles-329509_recursos_1.pdf

OMS (2001). Clasificación Internacional del Funcionamiento, las Discapacidades y la Salud. Ginebra: OMS.

Palacios, A. (2008) El Modelo Social de Discapacidad: orígenes, caracterización y plasmación en la Convención Internacional sobre los Derechos de las Personas con Discapacidad. Colección CIRMI No. 36. Ediciones Cinca. España.

Palacios, A. \& Romañach, J. (2005) El modelo de la diversidad. La Bioética y los Derechos Humanos como herramientas para alcanzar la plena Dignidad en la diversidad funcional. Editorial Diversitas. España.

REPÚBLICA DE COLOMBIA. (1991). Constitución Política de Colombia 1991. Santafé de Bogotá, Ediciones J.R. Bernal.

Strauss, A. y Corbin, J. (1990). Basics of qualitiveresearch. Grounded theory prodedures and techniques. California. Edi. Sage

Verdugo, M. y Shalock, R. (2010). Últimos avances en el enfoque de y concepción de las personas con discapacidad intelectual. Revista Siglo Cero. Revista española sobre discapacidad intelectual. Vol. 41 (4). № 236.

Vidal, F. (2000). El devenir de la familia. Articulo disponible en: http://www.psicoterapeutas.org/devenir.htm. 